\title{
Monitoring the Turmeric Finger Disease and Growth Characteristics Using Sensor Based Embedded System -A Novel Method
}

\author{
Maheswaran Shanmugam¹, Asokan Ramasamy², Sivaranjani Paramasivam¹, \\ Priyadharshini Prabhakaran1 \\ ${ }^{1}$ Department of ECE, Kongu Engineering College, Erode, India \\ ${ }^{2}$ Kongu Nadu College of Engineering and Technology, Trichy, India \\ Email: mmaheswaran_eie@rediffmail.com,mmaheswaran_eie@yahoo.com, asokece@yahoo.com, \\ sivaranjanipece@gmail.com, priyadharshini41ppd@gmail.com
}

Received 26 March 2016; accepted 28 April 2016; published 7 June 2016

Copyright (C) 2016 by authors and Scientific Research Publishing Inc.

This work is licensed under the Creative Commons Attribution International License (CC BY). http://creativecommons.org/licenses/by/4.0/

c) (i) Open Access

\begin{abstract}
In this cyber era, novelty plays a prime role in the field of agriculture that majorly depends on computer-based measurements and control. Herein before, it was totally controlled and performed by the agriculturists. One of the technological innovative methods to measure and monitor the turmeric finger growth characteristics is the embedded system that is based on sensor array module such as flex sensor, temperature sensor and $\mathrm{pH}$ sensor. The experimental work has been designed and tested with five set of nodes and the growth of turmeric finger is tenuously monitored by measuring the change in flex resistance. Out of five nodes, two nodes were diseased. Deliberately, one node was left as such and the other node was treated with natural pesticides (pseudomonas and viride) to restrict the rhizome rot disease attack. After cultivation, it was found that the rhizome rot disease attack on the node which was treated with pesticides was comparatively lesser than the other node. The five different nodes have been used in the experimental work with an average flex sensor resistance of $3.962 \mathrm{~cm} / \mathrm{k} \Omega$. In a nutshell, this proposed method manifests the farmers to detect the rhizome rot disease at its earlier stage and to prevent it as well by screening the growth of the turmeric fingers when it is under the soil.
\end{abstract}

\section{Keywords}

Embedded System, Turmeric Finger Growth, Rhizome Rot Disease, Natural Pesticides, Flex Sensor 


\section{Introduction}

Agriculture is acquiring more importance in the ongoing modern era with the incorporation of computer integrated technology and application of advanced control systems [1]. Nowadays, the agribusiness increasingly banks on automation using computer based systems and usage of robotics for replacing the activities performed by man power, usually more superior in performance to human [2]. There is a huge demand in the production of machines required for agricultural land by integrating computer, electromechanical and information systems due to the increasing complexity in performing farming [3].

The need for the new methodologies to meet the challenges of intricacy prevailing in the agricultural scenario has also led to the emergence of precision agriculture. Precision agriculture is very much useful in improving the efficiency of performance of agricultural land and also increases the quality and reliability in spite of the ruggedness in the environment [4]. The effect over the growth of crops due to the presence of obstacles in the internode's communication is compared with the performance of sensor node in the greenhouse environment running with low power operation by Hyun-Joong Kang [5]. The existing wireless sensor networks like ZigBee, Bluetooth and WiFi are operated with $2.4 \mathrm{GHz}$ Industrial Specific and Medical (ISM) band which are applicable for modern precision agriculture [6] [7]. All these wireless networks provide license free operation, huge spectrum allocation and worldwide compatibility [8]. Miranda [9] evaluated the irrigation amount based on distributed soil water measurements using closed loop systems.

"Indian Saffron" as it is called, the turmeric with a long past of 4000 years of medicinal usage and also as an integral part of drugs, cosmetics and dye industries. Nitrogen, phosphorus, potassium forms the vital nutrient requirement whereas the calcium, magnesium and Sulphur are the follow-on nutrients. The root characteristic is estimated using various sensors like flex sensor, temperature and $\mathrm{pH}$ sensors. The fingers of turmeric get affected by fungus during $4^{\text {th }}$ month of its growth and the rhizome rot disease is unpredictable because it is underground. The above mentioned rhizome rot diseases is noticed when it spreads out as "Leaf Spot" [10]. As this ruins the entire plant life, the flex sensor is used for continues monitoring and identified at earlier stage itself. After identification is done, then precautions can be made by applying pseudomonas and viride [11] [12] that serves as the best natural bio-pesticides.

In this research, an innovative method of investigating the turmeric finger growth with flex sensors using embedded system and the definite advantage of detection of rhizome rot disease in the earlier stage itself is proposed. The various sensors used are LM35 for temperature measurement and PHE-45P is used to measure soil $\mathrm{pH}$ range. The sensor array collects the data of n-number of nodes and transmits it individually using Zigbee module [13] that are collectively received and monitored using coordinating module and LCD display [14]. The GSM (Global System for Mobile Communications) is used to transmit the data to a remote monitoring location. The Zigbee module operates with a voltage and frequency of $3.3 \mathrm{~V}$ and $2.4 \mathrm{GHz}$ respectively covering 25 meters [15] [16] with an advantage of affordability and less power consumption than the other communication protocol (like RF, Bluetooth etc.) [15]. Number of sensor nodes depends on area of the field. One node covers $20 \mathrm{~m}^{2}$ area accordingly it is required to put number of nodes.

\section{Methodology}

\subsection{Field Instrumentation}

As shown in Figure 1, the experimental setup consists of three major components.

1) Field data measurement module [FDMM- 5 numbers].

2) Centre data processing module [CDPM].

3) Data logging and analysis module [DLAM].

To test this experimental setup 0.25 hectare of land was chosen. A module with five designed nodes had been put into practice without a specific location in the field to notify the readings from five nodes. Each field data measurement module (FDMM) comprised of a) temperature, b) $\mathrm{pH}$ and c) five flex sensors. The setup was kept at random in order to predict whether the turmeric finger was affected by the disease. Electrical signal outputs from temperature, $\mathrm{pH}$ and flex sensors were given to the signal conditioning unit so as to strengthen and sent to microcontroller's internal Analog to Digital Converter (ADC) module. The converted digital values were then processed into temperature value, $\mathrm{pH}$ value and flex resistance by the software in the microcontroller (LPC2148). The microcontroller was programmed to store values taken at three time intervals—8:00 am, 12:30 pm and 4:00 


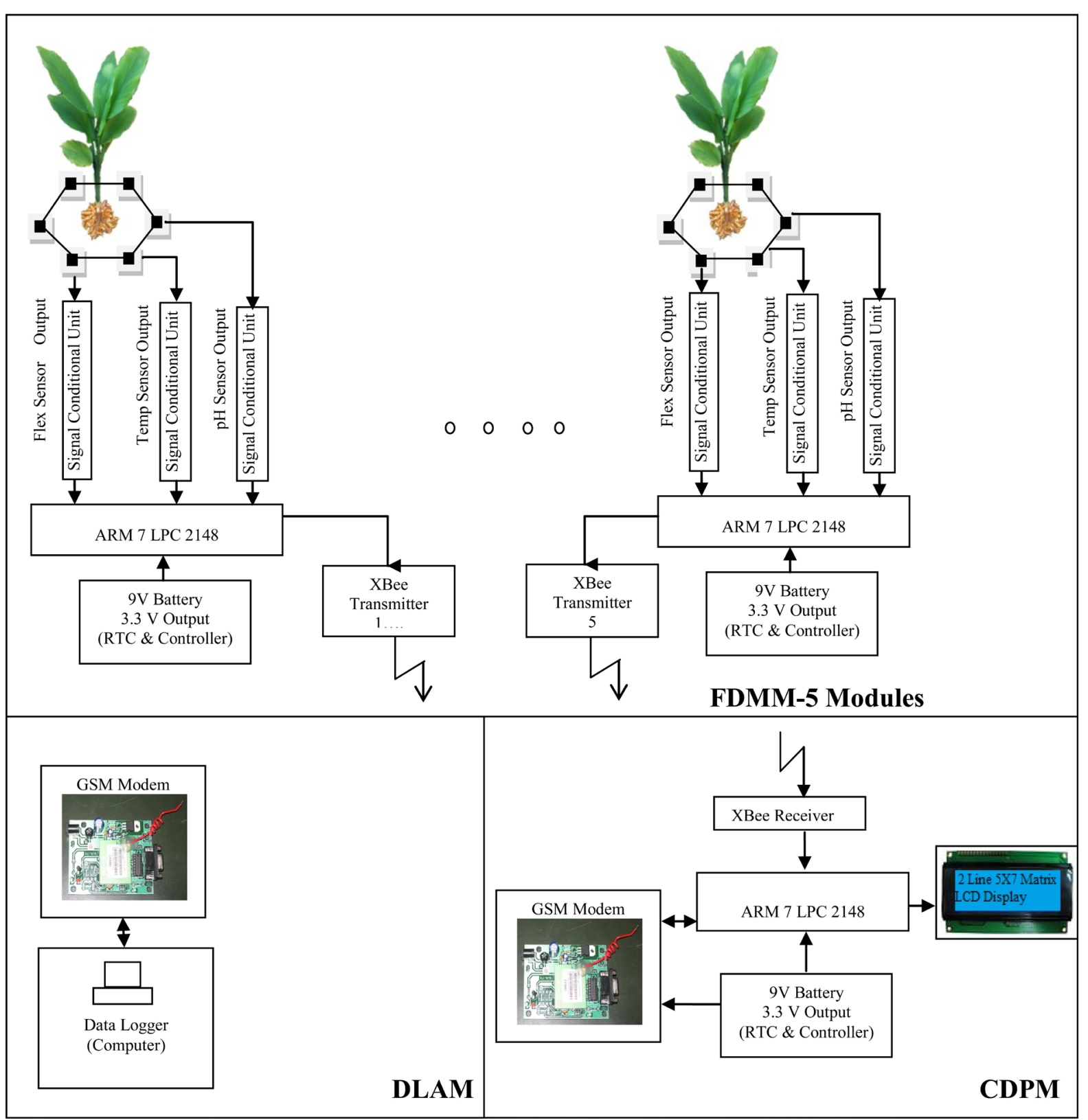

Figure 1. Methodology diagram.

pm on a regular basis. To minimize the power consumption, microcontroller's internal real time clock was programmed to find out and store the readings for about 3 days and the data were transferred to the centre co-ordinating node via ZigBee transmitter. The obtained data were sequentially transferred in the form of message to computer which was at remote location via GSM technology [17]. As and when the computer is ON, all the data which are transferred earlier will be updated in the system. All the nodes were operated with $9 \mathrm{~V} / 15 \mathrm{Ah}$ battery and had been charged once in 40 days except computer.

\subsubsection{Flex Sensor}

The flex sensor was used to assess the angle displacement of the crop and it is capable of bending physically. Robotics, Gaming (Virtual Motion), Medical Devices, Computer Peripherals, Musical Instruments Physical Therapy, Simple Construction and Low Profile are some of the other real time application of flex sensors. The array of five flex sensors were fixed in the specified position around the plant for observing the finger growth. 
The four sensors F1, F2, F3, and F4 had been fixed on four sides (around) of the plant. Whereas F5 was positioned at the tip of the plant to screen the descendent turmeric finger growth and it showed the maximum growth rate rather than the other sensors. The electrical resistance of flex sensor is $10 \mathrm{k} \Omega$ and the value varied pertinent to the force applied. The flex sensor has a power rating of about 0.5 Watts.

The flex sensor and its signal conditioning unit are shown in Figure 2 and Figure 3 respectively. The input impedance $R_{i n}$ tends to infinity and the feedback impedance $R_{f}$ decreases to zero in case of non-inverting configuration. $A$ feedback of $100 \%$ is given by directly connecting the output to the non-inverting terminal and $V_{\text {in }}$ is approximately equal to $V_{2}$ due to a fixed unity gain amplifier. The non-inverting input voltage $V_{\text {in }}$ and the amplifier gain is specified as follows (Equation (1) to Equation (3)):

$$
\text { Output voltage }\left(V_{2}\right)=A \times V_{\text {in }}
$$

(Gain $A=1$; Unity Gain)

$$
\text { So } V_{2}=V_{\text {in }}
$$

where

$$
V_{\text {in }}=5 \mathrm{~V}\left(\frac{R_{2}}{R_{1}+R_{2}}\right)=2.5 \mathrm{~V}
$$

$\mathrm{R}_{1}$ is the flex sensor resistance and varies accordingly to its bend.

The error due to the source impedance of flex sensor acting as a voltage divider is reduced by decreasing the bias current and then the operational amplifier can be used in the basic flex sensor circuit as an impedance buffer (Q1). Output from the operational amplifier is fed to the microcontroller 10 bit ADC.

$$
\text { Step size of the } \mathrm{ADC}(1 \mathrm{LSB})=\left(V_{R E F}-V_{\text {SSA }}\right) / 1024
$$

where $V_{R E F}=$ Reference voltage to ADC $(1 \mathrm{~V}), V_{S S A}=$ Analog Ground $(0 \mathrm{~V})$

Resolution $(1 \mathrm{LSB}=(1-0) / 1024=0.977 \mathrm{mv}$

The variance of resistance measurement was between $10.1 \mathrm{k} \Omega$ and $13.8 \mathrm{k} \Omega$. Hence output voltage from the

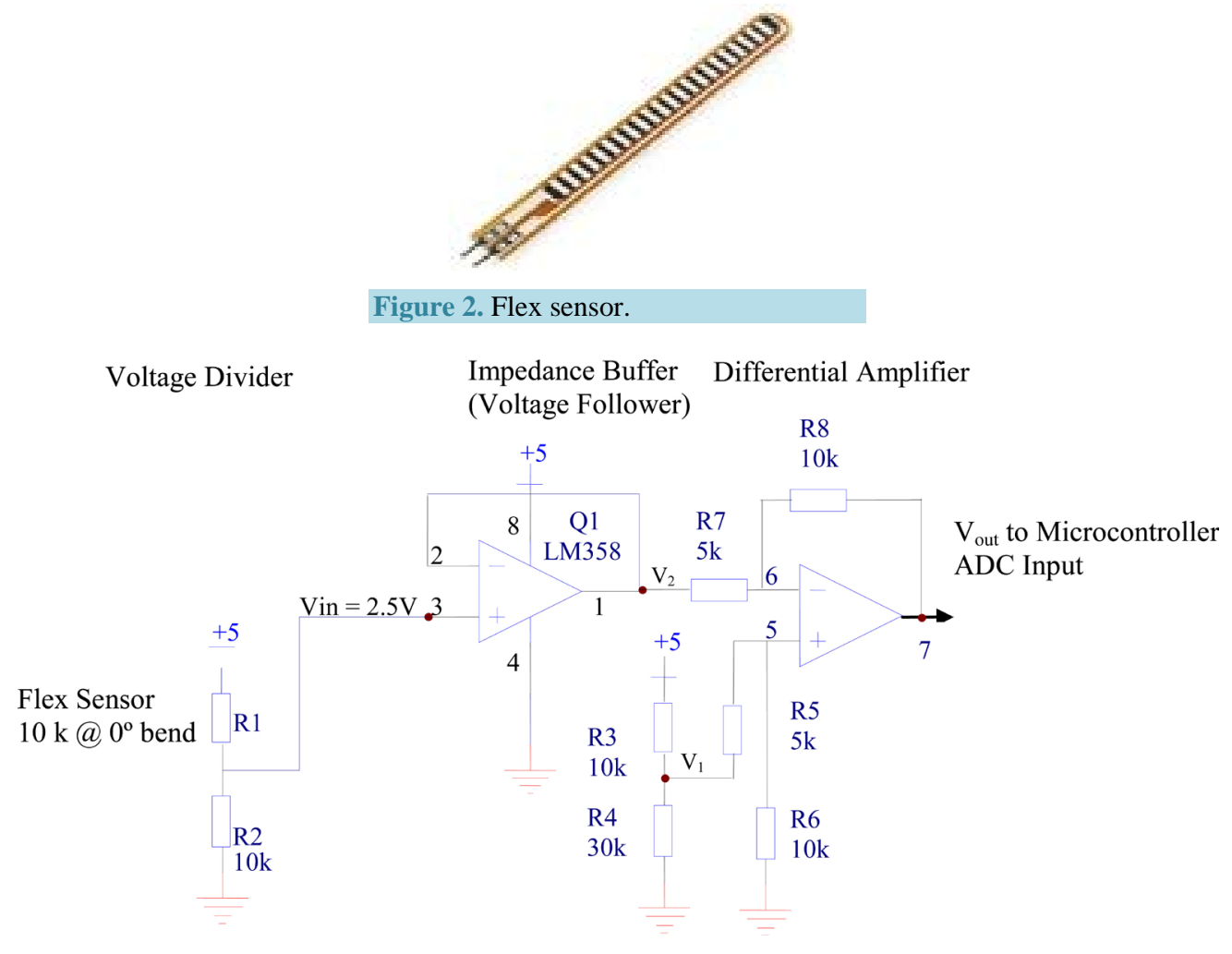

Figure 3. Flex sensor signal conditioning unit. 
impedance buffer was between $2.1008 \mathrm{~V}$ (for $13.8 \mathrm{k} \Omega$ ) and $2.4876 \mathrm{~V}$ (for $10.1 \mathrm{k} \Omega$ ) respecting the Equation (2). Due to the small variations in the voltage, it was required to increase the range of voltage by using differential amplifier. Voltage to the ADC circuit was computed by the Equation (4)

$$
V_{\text {out }}=\frac{R_{x}}{R_{y}}\left(V_{1}-V_{2}\right)
$$

where

$$
\begin{gathered}
R_{x}=R_{6}=R_{8}=10 \mathrm{k} \\
R_{y}=R_{5}=R_{7}=5 \mathrm{k} \\
V_{1}=2.5 \mathrm{~V} \\
V_{2}=\text { between } 2.1008 \mathrm{~V} \text { and } 2.4876 \mathrm{~V}
\end{gathered}
$$

According to the Equation (4), output voltage from differential amplifier was between $0.7984 \mathrm{~V}$ and $0.0248 \mathrm{~V}$. Since the flex sensor is more flexible [18], it was chosen to trace the growth of the turmeric finger. By the protrusion of the finger, the flex sensor had bent accordingly there was a change in resistance. To screen the finger growth, flex sensors were placed around the plant at the stage of planting itself.

\subsubsection{Temperature Sensor}

One of the precision integrated circuit temperature sensors are known as LM35 series. It is majorly used for remote applications and the output which is directly proportional to the centigrade [3]. For its operation, the LM35 series can use either a single or dual power supply. From the above supply provided it draws only $60 \mu \mathrm{A}$ and has low self-heating of $0.1^{\circ} \mathrm{C}$ in still air. In the LM35 series, the rated temperature range of LM35 is $-55^{\circ} \mathrm{C}$ to $150^{\circ} \mathrm{C}$ while LM35c provides improved accuracy of $-10^{\circ} \mathrm{C}$ with a range of $-40^{\circ} \mathrm{C}$ to $+110^{\circ} \mathrm{C}$.

The temperature measurement circuit diagram is shown in Figure 4. According to the Equation (3) the ADC resolution was $0.977 \mathrm{mV}$. Temperature varies between $17.1^{\circ} \mathrm{C}$ and $21.8^{\circ} \mathrm{C}$ and the corresponding output voltage from the sensor module was between $171 \mathrm{mV}$ and $218 \mathrm{mV}$. The temperature and $\mathrm{pH}$ sensors were used to determine the soil characteristics. In view of the fact that the temperature and the $\mathrm{pH}$ parameters vary during rainfall and fertilizer application, it's mandatory to examine the soil characteristics to enhance the plant growth. The performance of linear circuits connected with wires in an aggressive environment is affected due to intense electromagnetic radiation from transmitters, wires acting as receiving antennas and internal junctions forming rectifiers. The above mentioned problem can be eliminated using a bypass capacitor from $\mathrm{V}_{\text {in }}$ to ground (C2-0.01 $\left.\mu \mathrm{F}\right)$ and a series R-C damper, such as $75 \Omega(\mathrm{R} 1)$, in series with $1 \mu \mathrm{F} / 10 \mathrm{~V}$ (C1) from output to ground. Out of the three (flex sensor, temperature sensor and $\mathrm{pH}$ sensor) measurements, flex sensor was given much importance than the other two whose measurement acts as an effective technique for detecting the finger growth rhizome rot disease in turmeric plants at an early stage.

\subsection{3. pH Sensor}

The PHE-45P sensor measures the $\mathrm{pH}$ value of aqueous solution used in the industrial and municipal process application. PHE-45P electrode is made of glass and the PHE-45P sensor's glass electrode must be ensured to be

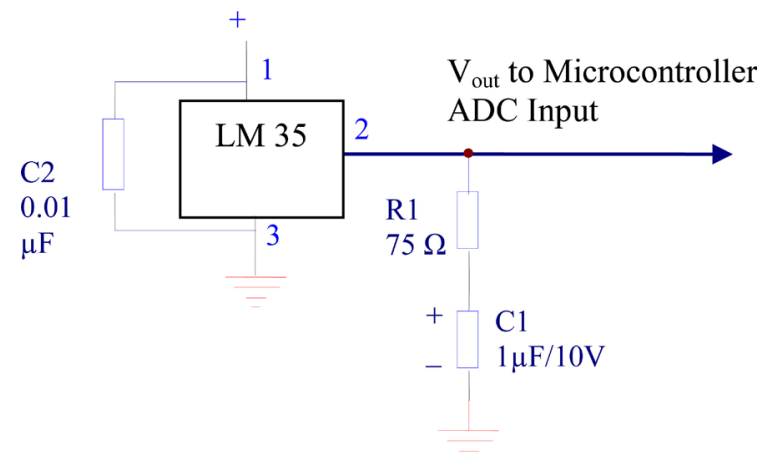

Figure 4. Temperature sensor circuit diagram. 
always wet for its proper functionality. These sensors are enabling immediate usage due to the fluid filled cap over it. In order to restore functionality, the electrode should be hydrated for 24 hours if it is dried and must be mounted vertically (electrode facing down) possible and also after purchasing the sensor. While mounting the angle of sensor must be at least $10^{\circ}$ above horizontal. The life time of the sensor is maximised using a high volume dual junction salt-bridge and the chance of fouling is minimised using the annular junction which provides a large surface area. Further the contamination of the reference solution is diminished using the large electrolyte volume and dual reference junctions. The second glass $\mathrm{pH}$ electrode immersed in a reference solution acts as the reference element and this reference system importantly increases the range of sensor applications.

The integrated preamplifier is attached with the sensor. The low impedance signal is created from the amplifier to fetch the stable readings in noisy environment. The electrode breakage, loss of sensor seal integrity or integral temperature element failure warning can be given to the user using the system diagnostics in the sensor. The temperature sensor used in PHE-45P is called Pt1000 RTD which is used for obtaining highly linear and accurate output.

To test the performance of the system (mainly on flex sensor), an artificial method of turmeric finger rhizome rot disease was caused by stacking the water for more than two days to some of the nodes.

\subsection{Data Logging and Communication}

\subsubsection{Centre Data Processing Module [CDPM]}

The CDPM module consists of one central co-ordinating node that collects the information on the five different nodes via Zigbee communication. On interrupt basis (periodic updates based on RTC), out of the five nodes, the CDPM module receives data and that has been communicated to DLAM module via GSM. The product of Zigbee is XBEE module which is primarily used for fulfilling the IEEE 802.15.4 standards and requirements of the wireless sensor networks such as low cost, low power [19]. The XBEE module is widely used for remote applications since the cost of the XBEE module is low [18]. The module working within the ISM $2.4 \mathrm{GHz}$ frequency band requires a minimal amount of power to exchange data between devices. In addition to the above, XBEE module provides pin-for-pin compatibility with each other.

\subsubsection{Data Logging and Analysis Module [DLAM]}

The DLAM module consists of one GSM receiver and one personal computer. GSM module receives the data and that has been converted to RS232 voltage (TTL logic to RS232 logic) by MAX232 IC. On both transmitter and receiver part SIM900 module has been used. After getting the data, data are being stored in the computer by using visual basic (VB) software for continuous monitoring of the parameter deviation.

\section{Results and Discussion}

A module has been designed with array sensors such as flex sensor, Temperature sensor and $\mathrm{pH}$ sensor which transmit data via the ZigBee module. Figure 5 and Figure 6 show the hardware and the implementation in the field.

\subsection{Soil pH Readings}

The moisture content of the soil was measured on watering and raining using $\mathrm{pH}$ readings as shown in the graph and the five different nodes 1 through node 5 were placed in different places under the soil. Figure 7(a) and Figure 7(b) graphs show the overall soil $\mathrm{pH}$ readings of five different sensor nodes. The $\mathrm{pH}$ value actually gets decreased after the occurrence of a rain or increased when fertilizers are applied. Both well and bore well are used to irrigate the field. The last two months (during the time of research) the water was highly scarce which made the farmers to use bore well increasing the $\mathrm{pH}$ value of the field and it is indicated using last ten set of reading. This led to the decrease in the chlorophyll content in large amount and the shade of the leaves turned to yellow. Chlorophyll is a green photosynthetic pigment playing a vital role in mounting the crop yield. The aforesaid fact had been discussed with the personnel of Coimbatore Agricultural University (Government of TamilNadu) and it was suggested that the supply of water during high $\mathrm{pH}$ value (above 6.3) can be considerably reduced and after watering once, the Nitrogen $(\mathrm{N})$ fertilizer could be used in the range between $10 \mathrm{~kg}$ and $25 \mathrm{~kg}$ per hectare depending on the $\mathrm{pH}$ value to compensate the change in $\mathrm{pH}$. 


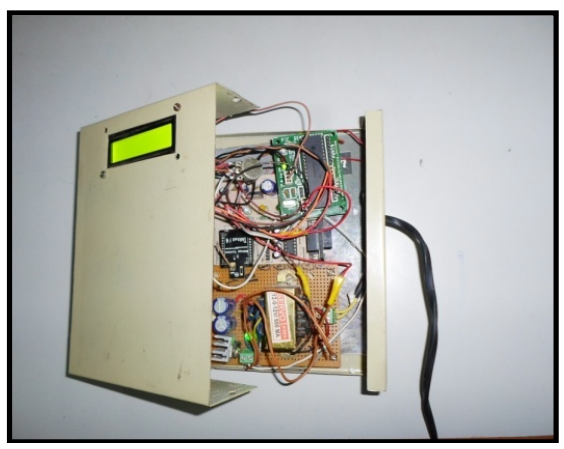

Figure 5. Front view of the module (CDPM).

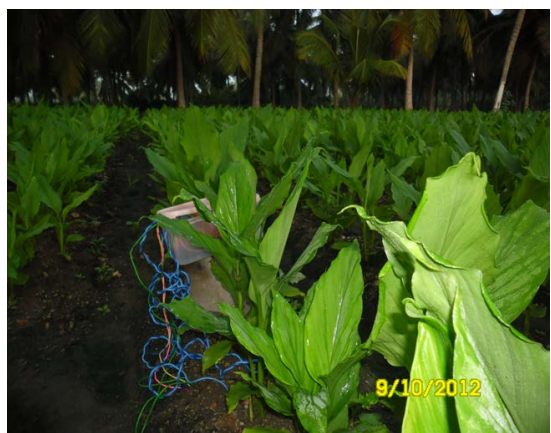

Figure 6. Designed module implemented in the field.

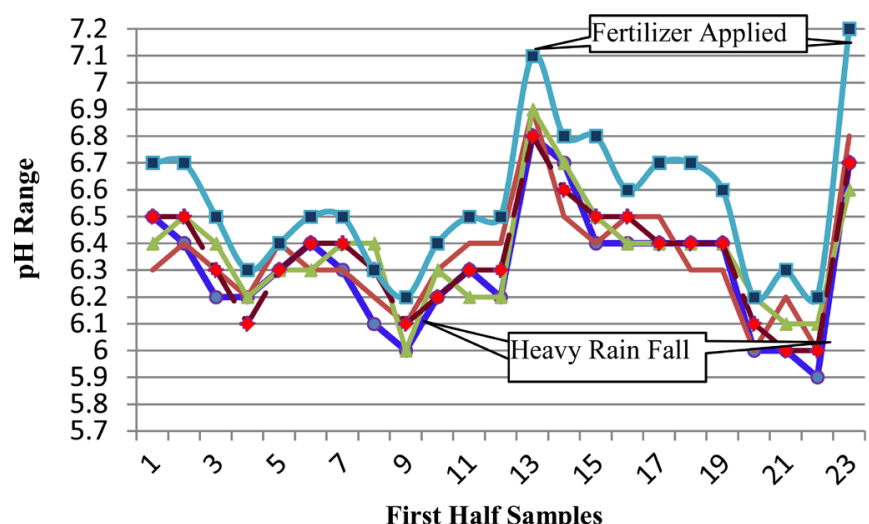

(a)

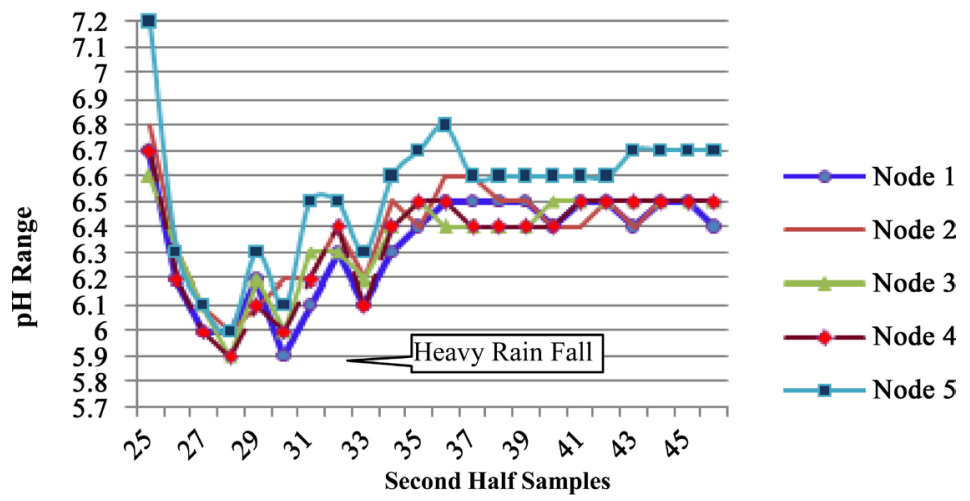

(b)

Figure 7. Graphs of $\mathrm{pH}$. 


\subsection{Soil Temperature Readings}

During rain, the inference was low in temperature and the awareness about the basic growing conditions of turmeric, the crop becomes strong and vibrant based on soil, water and atmospheric temperature. The proposed system was implemented in the month of May because turmeric is cultivated between the month of May and June. The temperature remains very high and also increases the soil temperature. All the nodes were watered during evening (between $5 \mathrm{pm}$ and $7 \mathrm{pm}$ ) except the node 2 and 5 which were watered during day time (between $11 \mathrm{am}$ and $2 \mathrm{pm}$ ). From Figure 8 graphs, some of the readings directly reflected the high temperature because of water supplied at noon. Thus the perfect timing for watering is early mornings or late evenings where the temperature is maintained between $17^{\circ} \mathrm{C}$ and $18^{\circ} \mathrm{C}$ to increase the yield.

\subsection{Flex Sensor Readings}

In an array of flex sensors N1 through N5 represents the individual node that consists of 5 sensors ( 5 flex sensor $($ F1 to F5) $\times 5$ nodes $=25$ sensors were used). The positions of five individual flex sensors are shown in the following Figure 9.

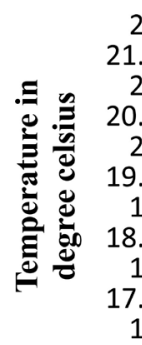

22
.5
21
.5
20
.5
19
.5
18
.5
17

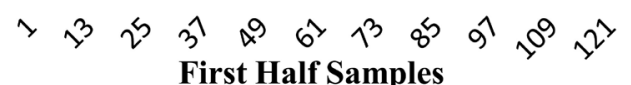

First Half Samples

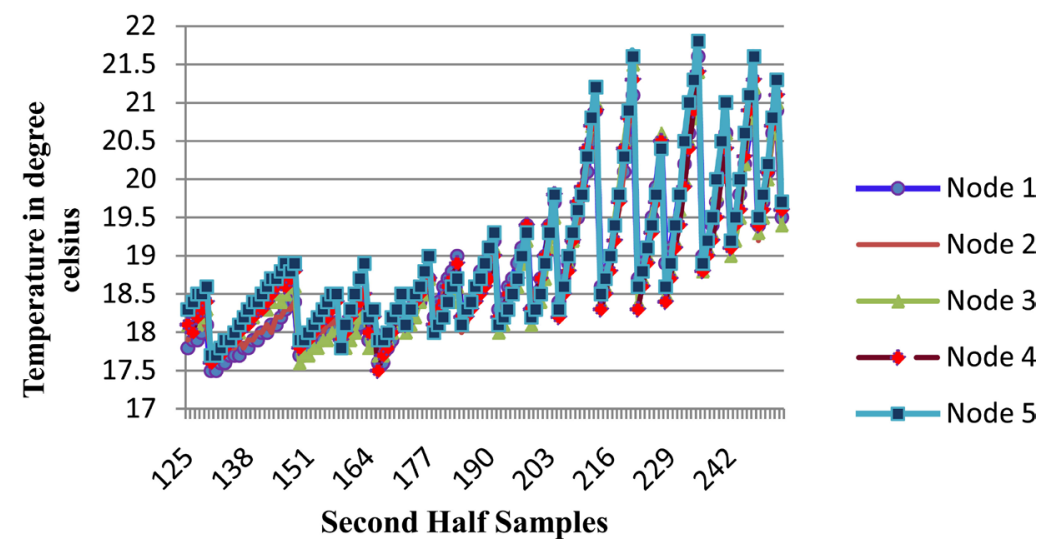

Figure 8. Graph of temperature.

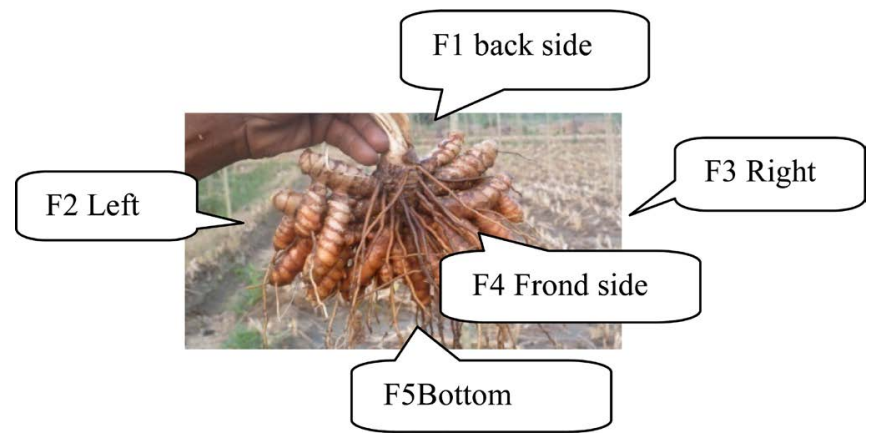

Figure 9. Positions of flex sensors.

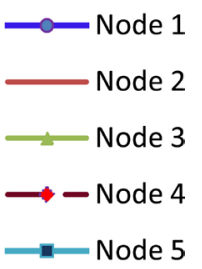




\subsubsection{Node 1}

Figure 10 graph shows the growth rate measurement based on readings taken at regular interval of the turmeric finger (node 1). Figure 11 shows the output image of the turmeric finger (node 1).

\section{Growth Result}

Table 1 indicates the growth rate of the turmeric finger $(\mathrm{cm})$ in accordance with the change in the resistance of the flex sensor-node 1 (after cultivation).The difference between minimum (initial) and maximum (final) resistance was used to obtain the following table at the end of the cultivation and finger length based on the actual physical measurement (cm scale) with respect to the centre of turmeric [20]. The same procedure was followed for all the finger growth measurements.

Node average growth rate with respective to flex sensor resistance $G_{\text {avg }}$ is found using the Equation (5).

$$
G_{\text {avg }}=\left(\sum_{k=1}^{n} F_{k}\right) /\left(\sum_{k=1}^{n} R_{k}\right) \mathrm{cm} / \mathrm{k} \Omega
$$

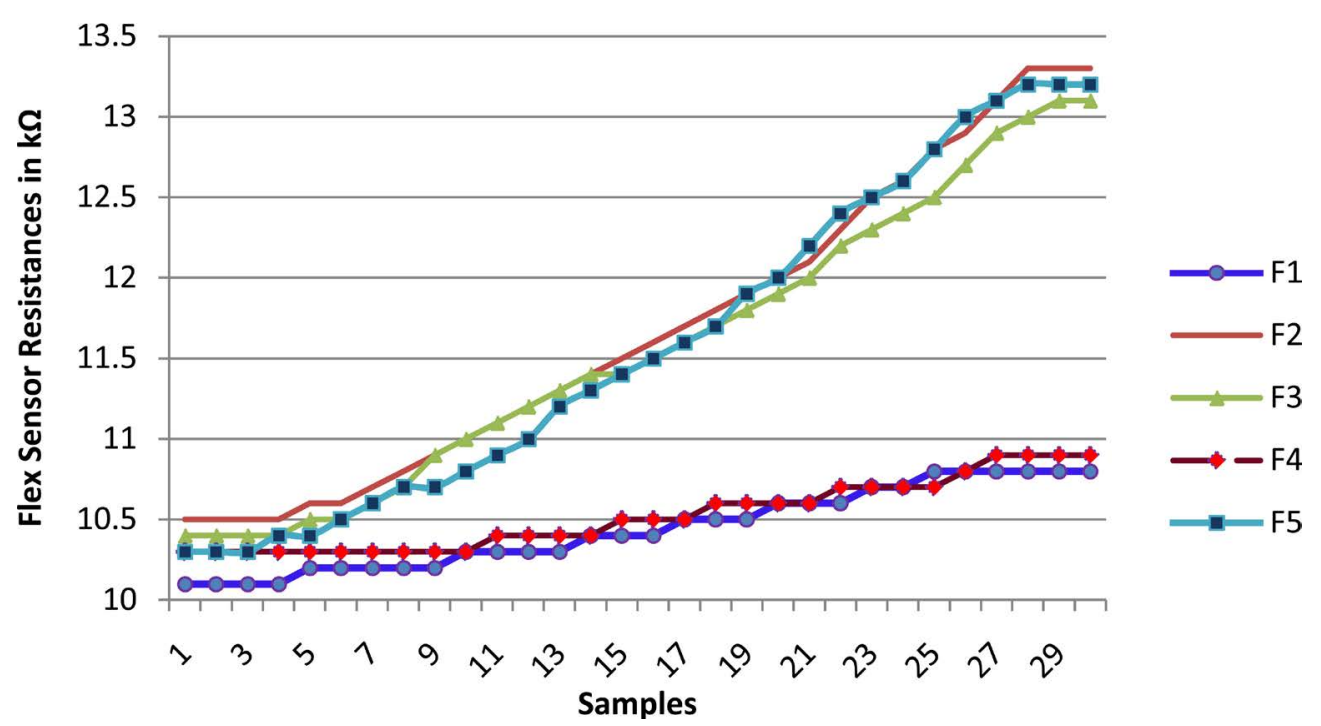

Figure 10. Graph of flex sensor-node 1.

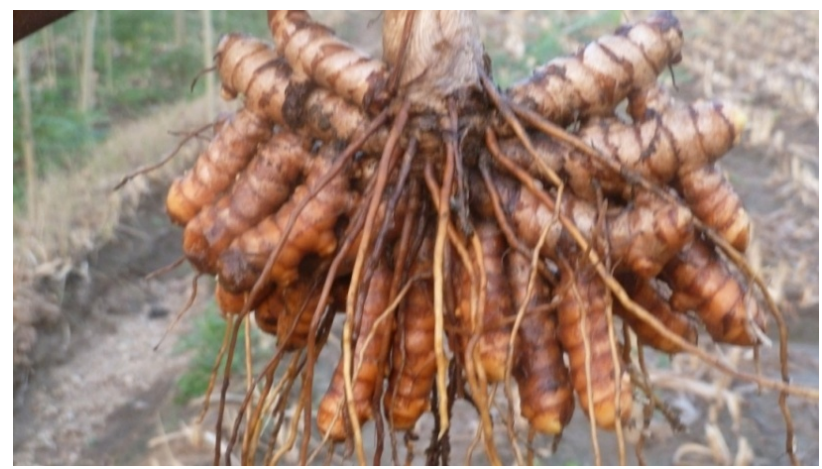

Figure 11. Output image-node 1.

Table 1. Growth result-node 1.

\begin{tabular}{cc}
\hline CHANGE IN RESISTANCE $(\mathrm{k} \Omega)$ & FINGER LENGTH $(\mathrm{cm})$ \\
\hline 0.6 & 2.4 \\
0.7 & 2.8 \\
2.7 & 10.6 \\
2.8 & 11.1 \\
2.9 & 11.5 \\
\hline
\end{tabular}


where

$F=$ Finger length in $\mathrm{cm}$

$R=$ Change in resistance in kilo ohm

$n=$ Number of distinguished reading during measurement

$$
G_{\text {avg }}=3.96 \mathrm{~cm} / \mathrm{k} \Omega
$$

Figure 12 graph shows the relationship between the turmeric finger growth $(\mathrm{cm})$ and the change in resistance $(R)$ of the flex sensor-node 1 . The measurement of finger growth is identified only after cultivation which is the normal practice that existed among farmers and they never get a chance to view the finger during cultivation. The finger growth of N1 and N4 was not much when compared to that of the other nodes. On the contrary, N2 had more growth than others. As turmeric is one of the row crops, the finger direction and the number of fingers depend on it [21]. In node-1, an average flex sensor resistance relating to the finger growth had been calculated as $3.96 \mathrm{~cm} / \mathrm{k} \Omega$. The number of primary and secondary finger branches was 7 and 16 respectively. The maximum length of the finger was $11.5 \mathrm{~cm}$ and the minimum length was $2.4 \mathrm{~cm}$ and the yield was $0.429 \mathrm{~kg}$. After steam and dry process, the polished turmeric yield was $0.085 \mathrm{~kg}$ for sale. Node 1 had been kept in the middle of the row, there was minimum space between the crops with that of the standard distance [22] and so the yield was average. Naturally, there was no Rhizome rot disease attack in node 1.

\subsubsection{Node 2}

Figure 13 graph shows the growth rate measurement based on readings taken at regular interval of the turmeric finger (node 2).

Figure 14 shows the output image of the turmeric finger (node 2).

\section{Growth Result}

Table 2 indicates the growth rate of the turmeric finger $(\mathrm{cm})$ in conforming to the change in the resistance of the flex sensor-node 2 (after cultivation).

Figure 15 graph shows the relationship between the turmeric finger growth $(\mathrm{cm})$ and the variance in resistance $(R)$ of the flex sensor-node 2 . Node average growth rate appropriate with flex sensor resistance $G_{a v g}$ was found using the Equation (7).

$$
G_{\text {avg }}=3.96 \mathrm{~cm} / \mathrm{k} \Omega
$$

The average flex resistance with respect to the finger growth is $3.96 \mathrm{~cm} / \mathrm{k} \Omega$ in the node 2 with 7 and 12 numbers of primary and secondary branches. The maximum and minimum length of finger was $10.3 \mathrm{~cm}$ and $2.4 \mathrm{~cm}$ respectively with the yield of $0.273 \mathrm{~kg}$. The polished turmeric yield was $0.055 \mathrm{~kg}$ for sale after the steam and dry process. The yield was average because the node 2 had kept in the middle of the row with an optimum distance between the crops.

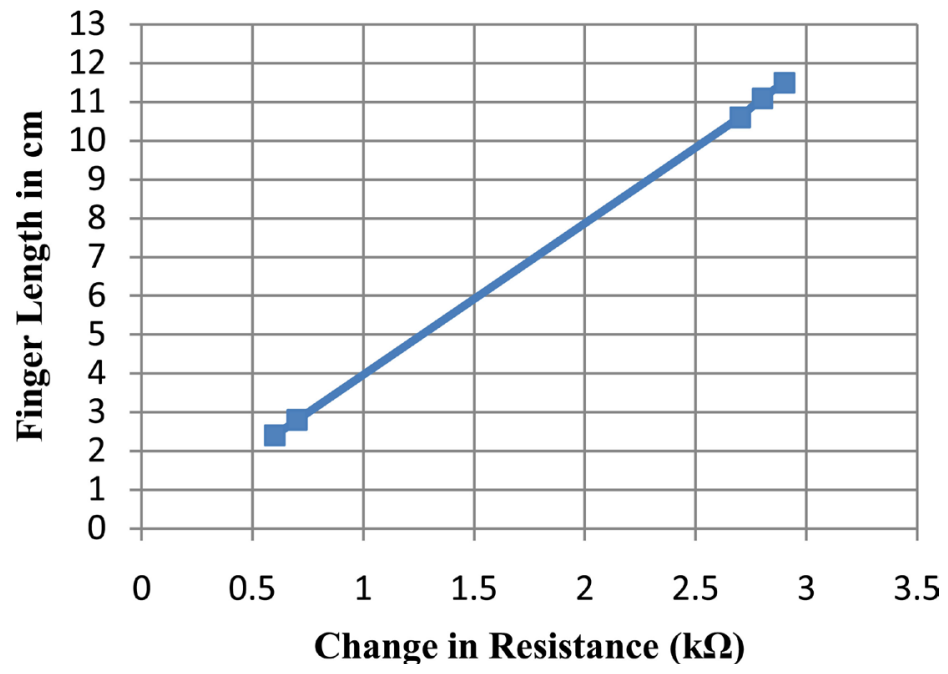

Figure 12. Graph of growth result-node 1. 


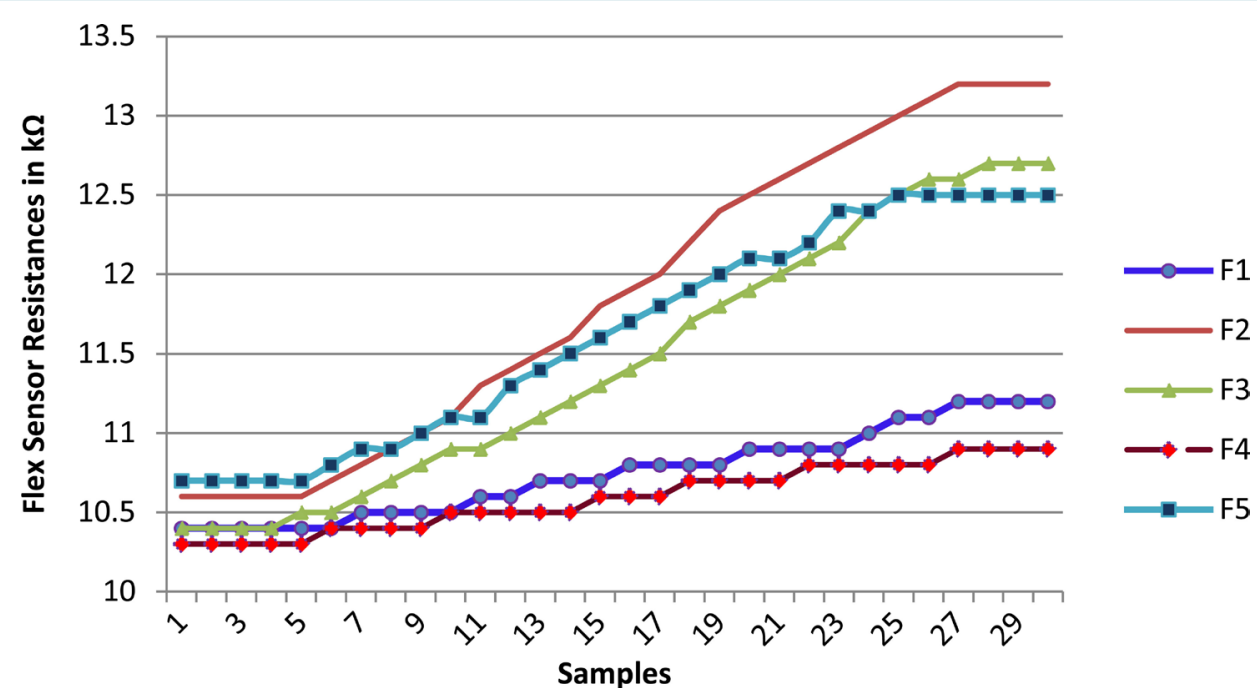

Figure 13. Graph of flex sensor-node 2.

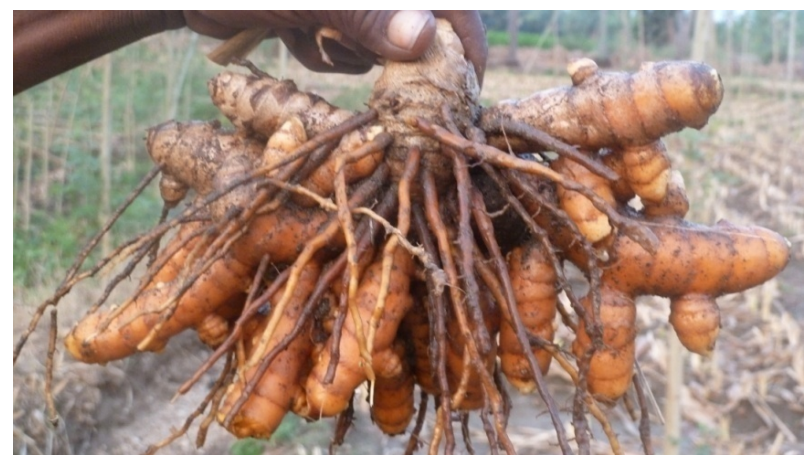

Figure 14. Output image-node 2.

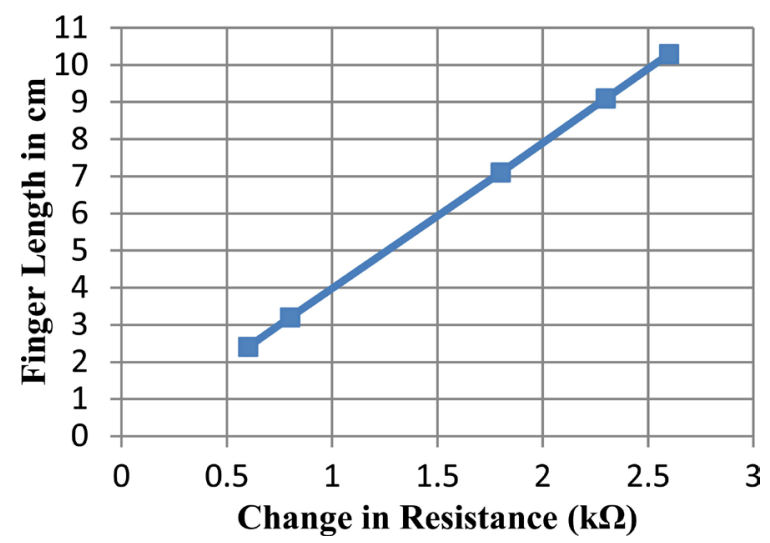

Figure 15. Graph of growth result-node 2.

Table 2. Growth result-node 2.

$\begin{array}{cc}\text { CHANGE IN RESISTANCE }(\mathrm{k} \Omega) & \text { FINGER LENGTH }(\mathrm{cm}) \\ 0.6 & 2.4 \\ 0.8 & 3.2 \\ 1.8 & 7.1 \\ 2.3 & 9.1 \\ 2.6 & 10.3\end{array}$




\subsubsection{Node 3}

Figure 16 graph shows the growth rate measurement based on readings taken at regular interval of the turmeric finger (node 3).

Figure 17 shows the output image of the turmeric finger (node 3).

\section{Growth Result}

Table 3 indicates the growth rate of the turmeric finger $(\mathrm{cm})$ in accordance with the change in the resistance of the flex sensor-node 3 (after cultivation)

Figure 18 graph shows the relationship between the turmeric finger growth $(\mathrm{cm})$ and the change in resistance $(R)$ of the flex sensor-node 3. Node average growth rate with respect to flex sensor resistance $G_{\text {avg }}$ was found using the Equation (8).

$$
G_{\text {avg }}=3.97 \mathrm{~cm}
$$

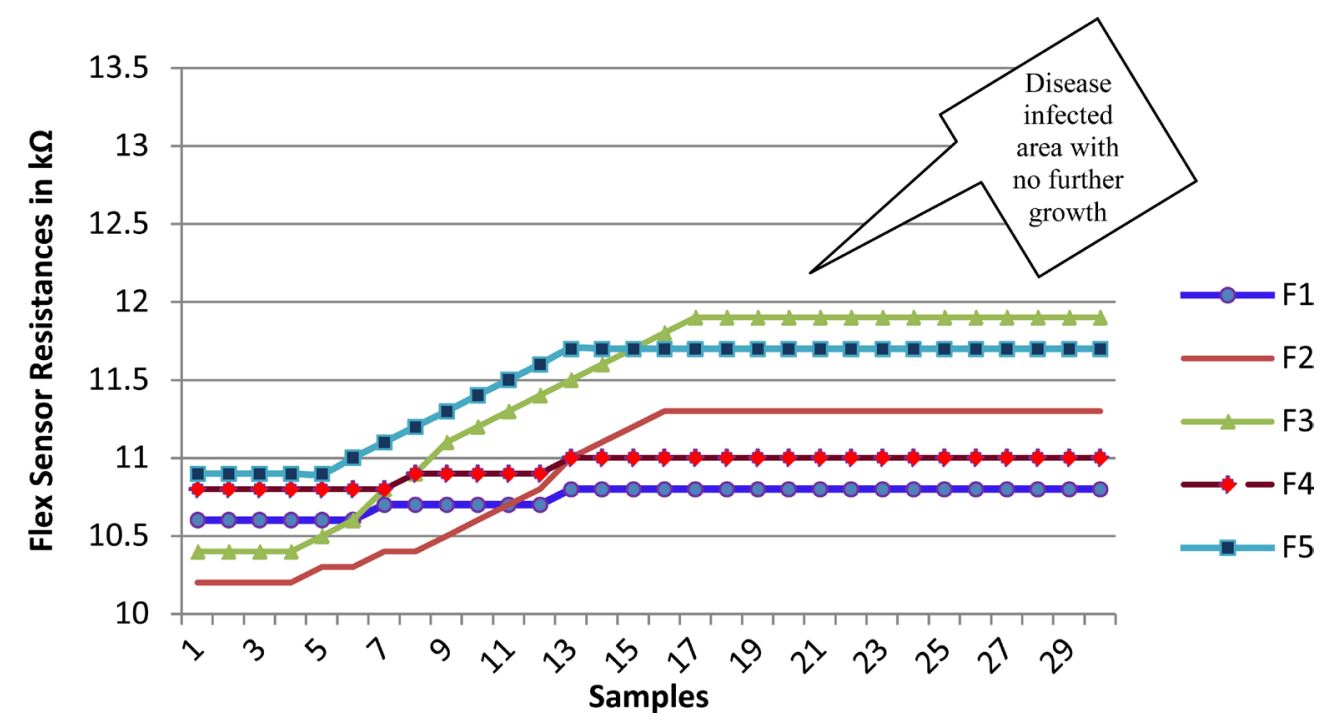

Figure 16. Graph of flex sensor-node 3.

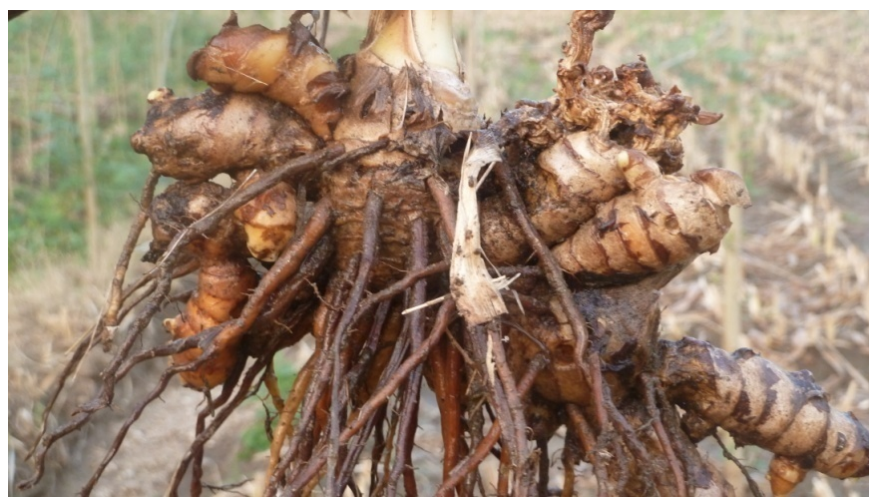

Figure 17. Output image-node 3.

Table 3. Growth result-node 3.

\begin{tabular}{cc}
\hline CHANGE IN RESISTANCE $(\mathrm{k} \Omega)$ & FINGER LENGTH $(\mathrm{cm})$ \\
\hline 0.2 & 0.8 \\
0.2 & 0.8 \\
0.8 & 3.2 \\
1.1 & 4.3 \\
1.5 & 6 \\
\hline
\end{tabular}




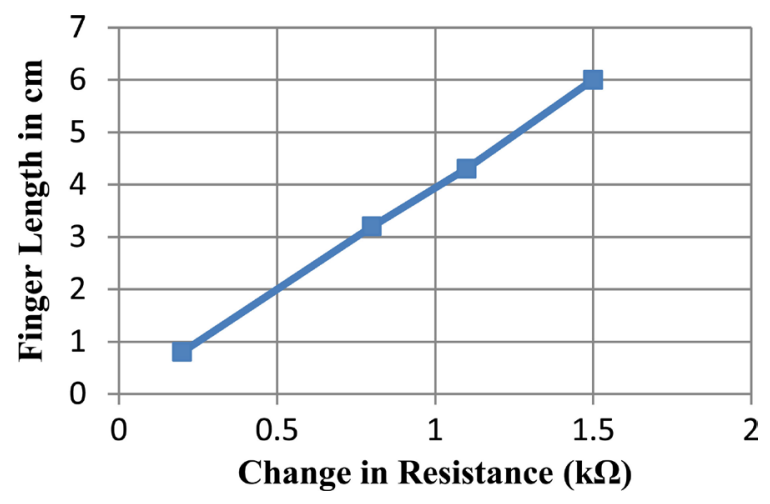

Figure 18. Graph of growth result-node 3.

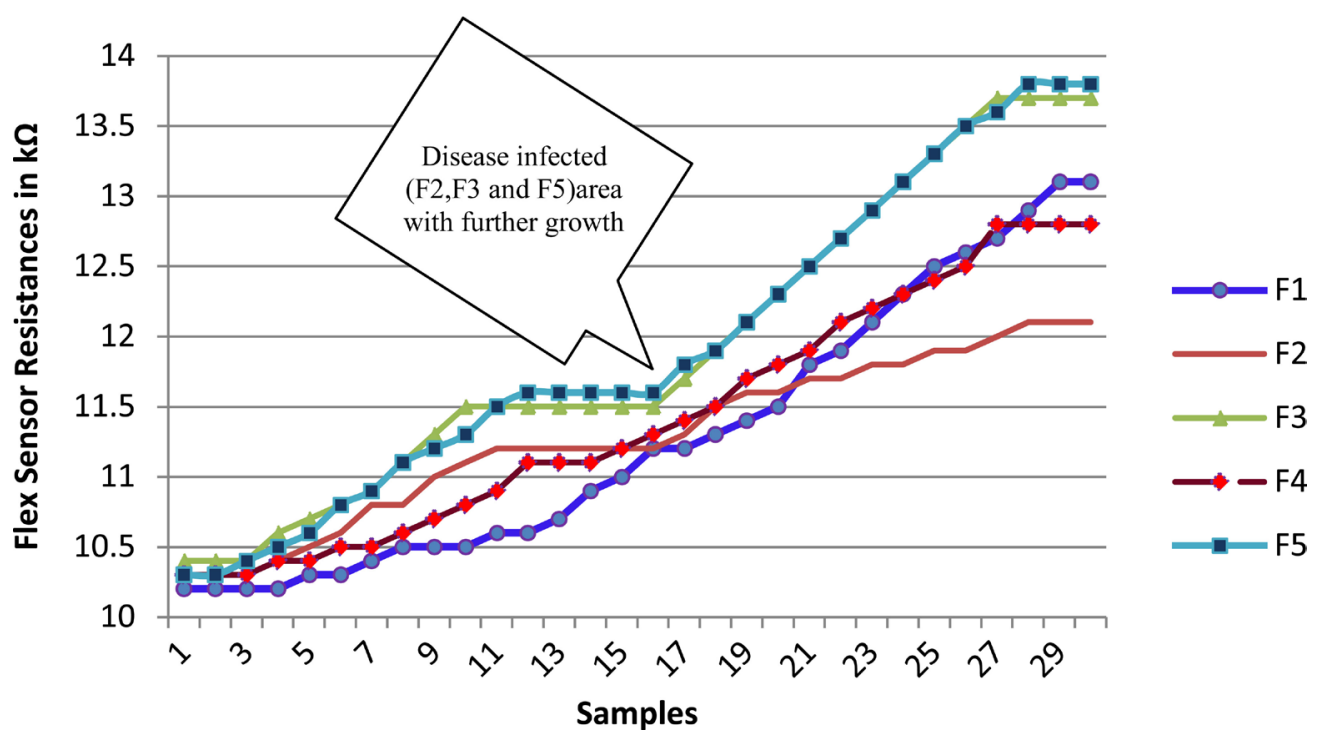

Figure 19. Graph of flex sensor-node 4.

The average flex resistance with respect to the finger growth is $3.96 \mathrm{~cm} / \mathrm{k} \Omega$ in the node 3 with 7 and 1 numbers of primary and secondary branches. The maximum and minimum length of finger was $6 \mathrm{~cm}$ and $0.8 \mathrm{~cm}$ respectively with the yield of $0.127 \mathrm{~kg}$. The polished turmeric yield was $0.025 \mathrm{~kg}$ for sale after the steam and dry process. An artificial method of turmeric finger Rhizome rot disease was caused by stacking water for more than two days. Hence the yield was very low. The natural pesticides like pseudomonas and viride were not intentionally applied on the affected turmeric crop (node 3 ) for testing the rhizome rot disease.

\subsubsection{Node 4}

Figure 19 graph shows the growth rate measurement based on readings taken at regular interval of the turmeric finger (node 4).

Figure 20 shows the output image of the turmeric finger (node 4).

Growth Result

Table 4 indicates the growth rate of the turmeric finger $(\mathrm{cm})$ in accordance with the change in the resistance of the flex sensor-node 4 (after cultivation).

Figure 21 graph shows the relationship between the turmeric finger growth $(\mathrm{cm})$ and the difference in resistance $(R)$ of the flex sensor-node 4 . Node average growth rate with respect to flex sensor resistance $G_{\text {avg }}$ was found using the Equation (9).

$$
G_{\text {avg }}=3.96 \mathrm{~cm} / \mathrm{k} \Omega
$$

The average flex resistance with respect to the finger growth is $3.96 \mathrm{~cm} / \mathrm{k} \Omega$ in the node 4 with 12 and 25 


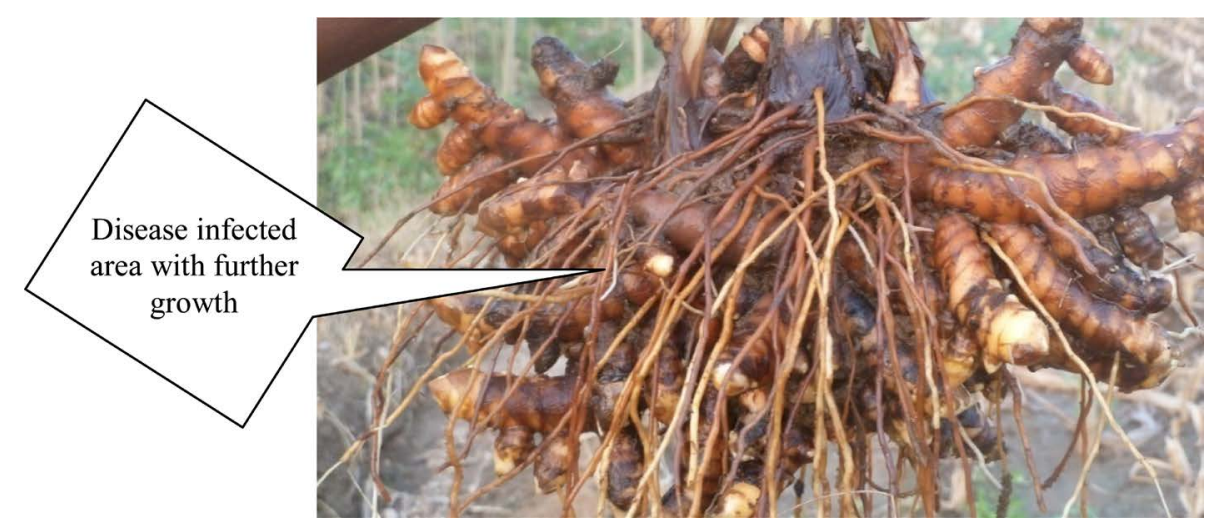

Figure 20. Output image-node 4.

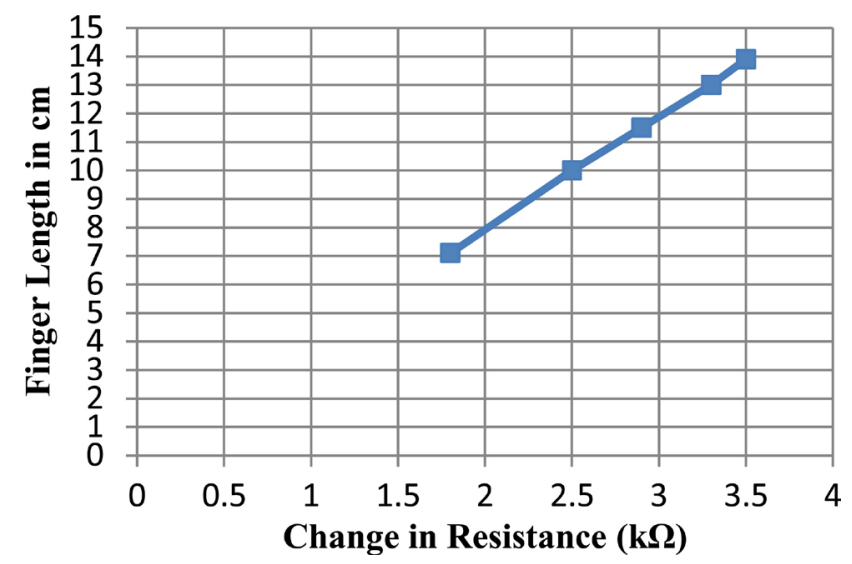

Figure 21. Graph of growth result-node 4.

Table 4. Growth result-node 4.

\begin{tabular}{cc}
\hline CHANGE IN RESISTANCE $(\mathrm{k} \Omega)$ & FINGER LENGTH $(\mathrm{cm})$ \\
\hline 1.8 & 7.1 \\
2.5 & 10 \\
2.9 & 11.5 \\
3.3 & 13 \\
3.5 & 13.9 \\
\hline
\end{tabular}

numbers of primary and secondary branches. The maximum and minimum length of finger was $13.9 \mathrm{~cm}$ and 7.1 $\mathrm{cm}$ respectively with the yield of $1.396 \mathrm{~kg}$. The polished turmeric yield was $0.28 \mathrm{~kg}$ for sale after the steam and dry process. The distance between the crops was optimum in node 4 which is kept in the middle of the row [22] and an artificial method of turmeric finger. Rhizome rot disease was caused by stacking water for more than two days. The natural pesticides like pseudomonas and viride were applied on the affected crop (node 4) for testing the rhizome rot disease.

Initially, it was found that there was growth in all nodes (F1, F2, F3, F4 and F5 of node 4) and at the middle (F2, F3 and F5) there were no further improvements in the growth. Thereby, it was identified that the above said nodes were attacked by Rhizome rot disease. After identifying the Rhizome rot disease, natural pesticides (pseudomonas and viride) were applied which resulted in an improvement on those nodes. The yield was more as compared to that of the node 3 which was affected and not treated for rhizome rot disease.

\subsubsection{Node 5}

Figure 22 graph shows the growth rate measurement based on readings taken at regular interval of the turmeric 
finger (node 5).

Figure 23 shows the output image of the turmeric finger (node 5).

Growth Result

Table 5 indicates the growth rate of the turmeric finger $(\mathrm{cm})$ in accordance with the change in the resistance of the flex sensor-node 5 (after cultivation).

Figure 24 graph shows the relationship between the turmeric finger growth $(\mathrm{cm})$ and the deviation in resistance $(R)$ of the flex sensor-node 5. Node average growth rate with respect to flex sensor resistance $G_{\text {avg }}$ was found using the Equation (10).

$$
G_{\text {avg }}=3.96 \mathrm{~cm} / \mathrm{k} \Omega
$$

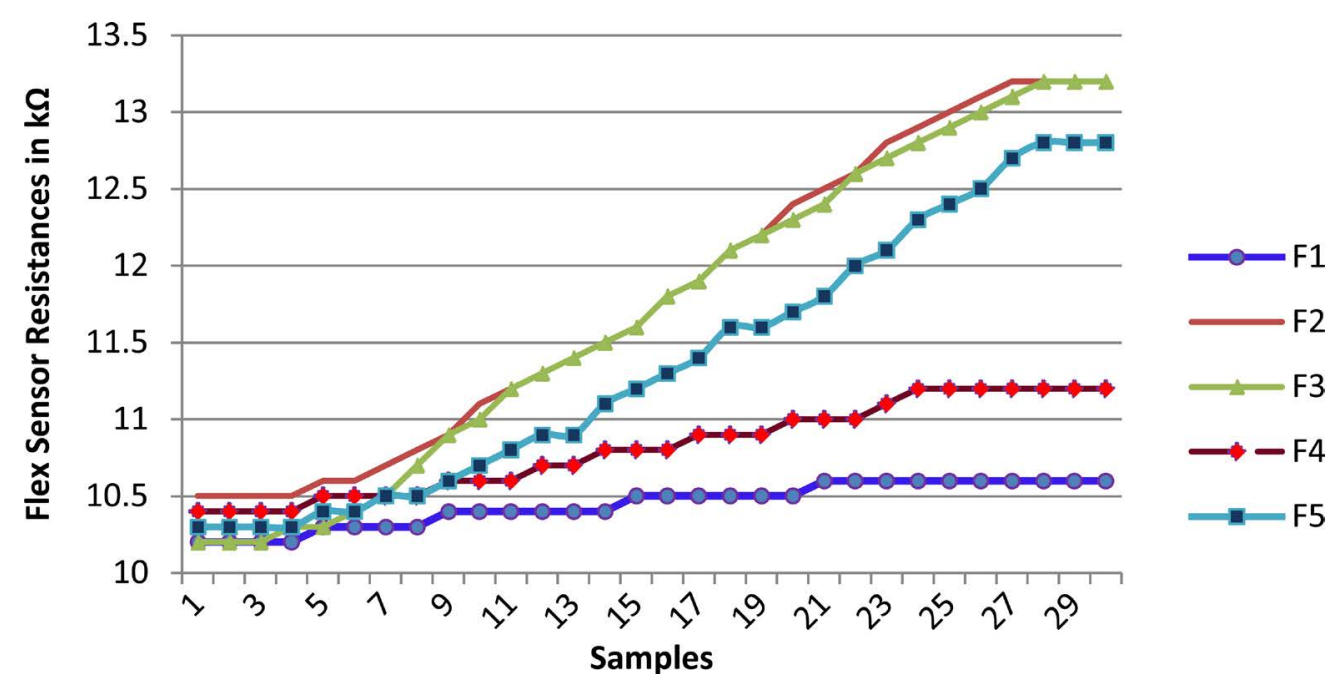

Figure 22. Graph of flex sensor-node 5.

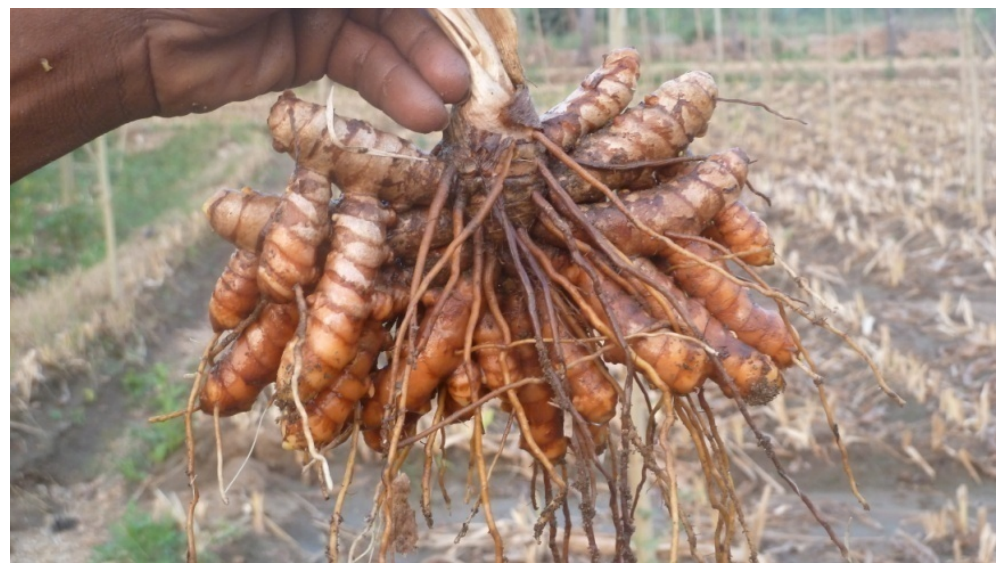

Figure 23. Output image-node 5.

Table 5. Growth result-node 5.

\begin{tabular}{cc}
\hline CHANGE IN RESISTANCE $(\mathrm{k} \Omega)$ & FINGER LENGTH $(\mathrm{cm})$ \\
\hline 0.4 & 1.6 \\
0.8 & 3.1 \\
2.5 & 9.9 \\
2.7 & 10.7 \\
3 & 11.9 \\
\hline
\end{tabular}




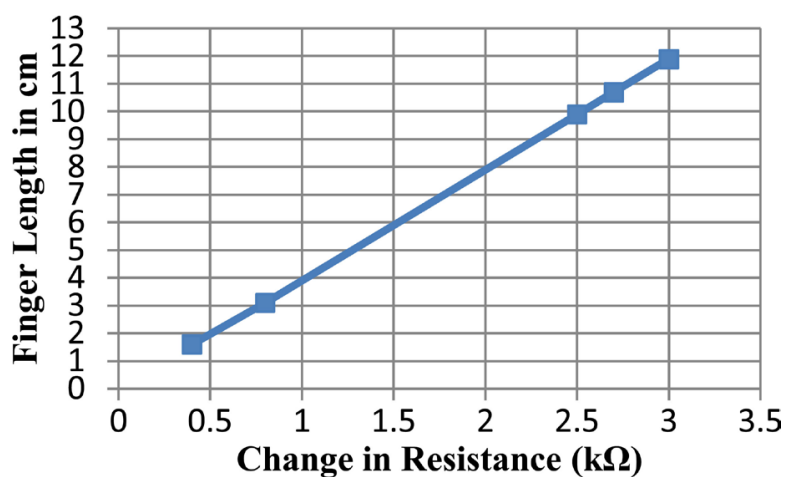

Figure 24. Graph of growth result-node 5.

The average flex resistance with respect to the finger growth is $3.96 \mathrm{~cm} / \mathrm{k} \Omega$ in the node 4 with 8 and 16 numbers of primary and secondary branches. The maximum and minimum length of finger was $11.9 \mathrm{~cm}$ and $1.6 \mathrm{~cm}$ respectively with the yield of $0.397 \mathrm{~kg}$. The polished turmeric yield was $0.08 \mathrm{~kg}$ for sale after the steam and dry process. Naturally, there was no Rhizome rot disease attack in node 5.

The application of nitrogen (N) and potash $\left(\mathrm{K}_{2} \mathrm{O}\right)$ as well as two micronutrients Zinc (Zn) and boron (B) play an essential role on growth and yield [23]. From the data of all nodes, it was obvious that only during the last four month; the turmeric finger had full-fledged growth. Therefore, monitoring the finger growth and applying the fertilizer at times, the farmers can get high yield in terms of weight and quality of the turmeric with high density which obtains more market prices. Modern precision agriculture requires adaption of lot more advanced technology [24] [25].

\section{Conclusion}

In the agricultural field at present the technology occupies a paramount position and it is important because agriculture forms the backbone of India occupying the major portion of economy by increasing its yield. The greatest requisites of this period are the amalgamation of computer technology in the agricultural field. By using embedded system, sensor array module with array of sensors such as flex sensor, temperature sensor and $\mathrm{pH}$ sensor were used to view the turmeric finger growth characteristics. The ZigBee and the GSM module had been used for communicating the data wirelessly and the overall growth rate had been estimated by examining the graph plotted on a daily analysis. The five different nodes have been used in the experimental work with an average flex sensor resistance of $3.962 \mathrm{~cm} / \mathrm{k} \Omega$. Of the five nodes, the node 3 and 4 were diseased and 3 was left as such purposely while the node 4 was treated with pseudomonas and viride to restrict the Rhizome rot disease. It was finally observed that node 4 contained comparatively less rhizome disease than node 3 . The definite advantage of this system is the early detection of the diseases and monitors the growth of the turmeric fingers when it is under the soil. By implementing this concept, farmers can be greatly guided to predict the final outcome by testing the growth rate and to take preventive measures in the early stage.

\section{References}

[1] Stipanicev, D. and Marasovic, J. (2003) Networked Embedded Greenhouse Monitoring and Control. Proceedings of the IEEE Conference on Control Applications, 2, 1350-1355. http://dx.doi.org/10.1109/cca.2003.1223208

[2] Yan, X.J., Lu, L.M. and Xu, L.Z. (2009) The Application of Wireless Sensor Network in the Irrigation Area Automatic System. Proceedings of the International Conference on Network Security, Wireless Communications and Trusted Computing (NSWCTC), 1, 21-24.

[3] Park, D.-H. and Park, J.-W. (2011) Wireless Sensor Network-Based Greenhouse Environment Monitoring and Automatic Control System for Dew Condensation Prevention. Sensors (Basel), 11, 3640-3651. http://dx.doi.org/10.3390/s110403640

[4] Gandino, F., Montrucchio, B., Rebaudengo, M. and Sanchex, E.R. (2009) On Improving Automation by Integrating RFID in the Traceability Management of the Agri-Food Sector. IEEE Transactions on Industrial Electronics, 56, 2357-2365. http://dx.doi.org/10.1109/TIE.2009.2019569

[5] Vieira, M.A.M., Coelho Jr., C.N., da Silva Jr., D.C. and da Mata, J.M. (2003) Survey on Wireless Sensor Network Devices. Proceedings of the IEEE Conference on Emerging Technologies and Factory Automation Proceedings, 1, 537-544. 
http://dx.doi.org/10.1109/etfa.2003.1247753

[6] Keshtgary, M. and Deljoo, A. (2012) An Efficient Wireless Sensor Network for Precision Agriculture. Canadian Journal on Multimedia and Wireless Networks, 3, 1-5.

[7] Chi, T., Chen, M. and Gao, Q. (2008) Implementation and Study of a Greenhouse Environment Surveillance System Based on Wireless Sensor Network. Proceedings of the IEEE/ASME International Conference on Mechtronic and Embedded Systems and Applications (MESA2008), Sichuan, 29-31 July 2008, 403-408. http://dx.doi.org/10.1109/icess.symposia.2008.44

[8] Chong, C.-Y. and Kumar, S.P. (2003) Sensor Networks: Evolution, Opportunities, and Challenges. Proceedings of the IEEE, 91, 1247-1256. http://dx.doi.org/10.1109/JPROC.2003.814918

[9] Yunseop, K., Evans, R.G. and Iversen, W.M. (2008) Remote Sensing and Control of an Irrigation System Using a Distributed Wireless Sensor Network. Proceedings of the IEEE Transaction on Instrumentation and Measurement, 57, 1379-1387. http://dx.doi.org/10.1109/tim.2008.917198

[10] Bharathi, V. and Sudhakar, R. (2011) Management of Rhizome rot of Turmeric (Curcuma longa L.) through IDM practices. Annals of Plant Protection Science, 19, 400-402.

[11] Ushamailini, C., Nakkeeran, S. and Marimuthu, T. (2008) Development of Biomanure for the Management of Turmeric Rhizome Rot. Archives of Phytopathology and Plant Protection, 41, 365-372. http://dx.doi.org/10.1080/03235400600796711

[12] Ramakrishnan, T.S. and Sowmini, C.K. (1954) Rhizome and Root Rot of Turmeric Caused by Pythium graminicolum Sub. Indian Phytopathology, 7, 152-159.

[13] Ahonen, Z., Virrankoski, T. and Elmusrati, R.M. (2008) Greenhouse Monitoring with Wireless Sensor. in Proceedings of the IEEE/ASME International Conference: Mechtronic and Embedded Systems and Applications (MESA2008), IEEE Xplore digital library,pp. 403-408,.

[14] Kang, B.J., Park, D.H., Cho, K.R., Shin, C.S., Cho, S.E. and Park, J.W. (2008) A Study on the Greenhouse Auto Control System Based on Wireless Sensor Network. Proceedings of the International Conference on Security Technology (SECTECH'08), Hainan Island, 13-15 December 2008, 41-44.

[15] Wang, W.H. and Cao, S.T. (2009) Application Research on Remote Intelligent monitoring System of Greenhouse Based on ZIGBEE WSN. Proceedings of the 2nd International Conference on Image and Signal Processing, Tianjin, 17-19 October 2009, 1-5.

[16] Zhou, Y.M., Yang, X.L., Guo, X.S., Zhou, M.G. and Wang, L.R. (2007) A Design of Greenhouse Monitoring \& Control System Based on ZigBee Wireless Sensor Network. International Conference on Wireless Communications, Networking and Mobile Computing, Shanghai, 21-25 September 2007, 2563-2567. http://dx.doi.org/10.1109/WICOM.2007.638

[17] Yan, H.W. and Pan, H.X. (2009) Remote Data Monitoring System Design Based on GSM Short Message Service. IEEE International Symposium on Industrial Electronics, Seoul, 5-8 July 2009, 364-367. http://dx.doi.org/10.1109/ISIE.2009.5218325

[18] Saggio, G., Lagati, A. and Orengo, G. (2012) Shaping Resistive Bend Sensors to Enhance Readout Linearity. ISRN Electronics, 2012, Article ID: 359759.

[19] He, G.M., Wang, X.C. and Sun, G.X. (2010) Design of a Greenhouse Humiture Monitoring System Based on Zigbee Wireless Sensor Networks. 5th International Conference on Frontier of Computer Science and Technology, Changchun, 18-22 August 2010, 361-365. http://dx.doi.org/10.1109/FCST.2010.10

[20] Kumar, B. and Gill, B.S. (2009) Effect of Method of Planting and Harvesting Time on Growth, Yield and Quality of Turmeric (Curcuma longa L.). Journal of Spices and Aromatic Crops, 18, 22-27.

[21] Cousins, M.W. and Adelberg, J.W. (2008) Short-term and Long-Term Time Course Studies of Turmeric (Curcuma longa L.) Micro Rhizome Development in Vitro. Plant Cell, Tissue and Organ Culture, 93, 283-293. http://dx.doi.org/10.1007/s11240-008-9375-z

[22] Kiran, M., Bibi, R., Jillani, M.S., Waseem, K., Ullah, G., Javeria, S. and Niamatullah, M. (2013) Effect of Plant Spacing on Profitable Yield of Turmeric (Curcuma longa L.). Pakistan Journal of Science, 65, 486-491.

[23] UmaDevi, G. (2008) Deployment of Organic and Inorganic Amendments to Manage Rhizome Rot of Turmeric. Journal of Mycology and Plant Pathology, 38, 307-310.

[24] Pawlowski, A., Guzman, J.L., Rodriguez, F., Berenguel, M., Sachez, J. and Dormido, S. (2009) Simulation of Greenhouse Climate Monitoring and Control with Wireless Sensor Networks and Event-Based Control. MDPI/Sensors, 9, 232-252.

[25] Ding, J.F., Zhao, J.Y. and Ma, B. (2009) Remote Monitoring System of Temperature and Humidity Based on GSM Image and Signal Processing. 2nd International Congress on Image and Signal Processing, Tianjin, 17-19 October 2009, 1-4. http://dx.doi.org/10.1109/CISP.2009.5304519 